\title{
Post Traumatic Growth for Gestational Diabetic Patients During COVID-19: Role of Partner Supportive Communication and Family Environment
}

\section{Zhidan Wang' \\ Alishba Hania ${ }^{2}$ \\ Asma Muzaffar ${ }^{2}$ \\ Saadia $\mathrm{Zia}^{2}$}

'School of Education Science, Jiangsu Normal University, Xuzhou, 22III6, People's Republic of China; ${ }^{2}$ Department of Psychology, Institute of Southern Punjab, Multan, Pakistan
Correspondence: Alishba Hania Email alishba_hania92@hotmail.com
Purpose: Leading a normal life and managing daily psychological or physical stress is hard for everybody but when a person is diagnosed with gestational diabetes mellitus (GDM) during a widespread pandemic, the battle is inescapable. This research aimed to explore some positive dimensions that can lessen the adversities of these women.

Design and Methods: We assessed all 200 cases of GDM who were registered in the maternity wards of the government and private hospitals of South Punjab, Pakistan. Respondents were diagnosed with GDM during the first wave of COVID-19. Posttraumatic growth (PTG) inventory, Family environment scale, and Partner supportive communication (PSC) scale were used. SEM and moderation analysis was conducted to test the hypothesized relationship among the variables.

Results: Result showed that elicitation of thoughts and feelings $(\beta=0.109, t$-value $=3.501$, $p=0.001)$, effective listening $(\beta=-0.144, t$-value $=1.928, p=0.054)$, and communication towards partner $(\beta=-0.209, t$-value $=4.850, p=0.005)$ significantly moderated the relationship between family environment and post traumatic growth.

Practical Implications: This research is beneficial for health practitioners because the trauma of being diagnosed with such a disease can be alleviated by the role of family environment and PSC.

Keywords: post-traumatic growth, partner supportive communication, family environment, gestational diabetes mellitus, GDM, PSC, PTG

\section{Introduction}

During the ongoing COVID-19pandemic), many people became mentally and physically challenged, but women with pregnancy complications went through additional stress. In the first wave of the outbreak, the initial mandatory step suggested by the pandemic management was to consider local lockdowns across all continents and it lead to a dramatic decrease in the number of prenatal visits. ${ }^{1}$ The primary goal of the health ministry was to maximize the capacity of all health care personnel concerning COVID-19 cases. This consequently created a challenge for medical facilities to launch any non-COVID-19 case priorities and patients were directed to opt for facilities such as telehealth, restricted accompanied visits, and grouping screening tests. ${ }^{1,2}$ Another potential drawback of the lockdown was psychological lethargy, unhealthy diet, and physical inactivity. ${ }^{3}$ Psychological lethargy is increased by the excessive intake of processed energy-dense food and limited energy expenditure, which can potentially lead to diabetes. ${ }^{4-6}$ The latter, 
suggesting a parallel existence of obesity and type 2 diabetes, ${ }^{7}$ can be related to risk factors such as hypertension and dyslipidemia.

Researchers conclude that multiple COVID-19 patients are at risk of a poor prognosis because of pre-existing comorbidities such as hypertension, diabetes, and pulmonary diseases. In particular, patients with diabetes and high body mass index are particularly susceptible to COVID-19 because of the challenged innate and adaptive immunity. Pregnancy is known to be associated with challenged glucose intolerance which can potentially lead to developing gestational diabetes mellitus (GDM). ${ }^{8}$ Although there is limited data on COVID-19 diagnosis in pregnant women, maternal mortality appears to be unaffected, while an increased risk of neonatal complications is seen. ${ }^{9,10} \mathrm{GDM}$ can be a post-natal effect of pregnancy and is a very serious concern for the physical and mental health of both mother and child. Alarmingly, the prevalence has recently increased in pregnant women. ${ }^{11}$ In Pakistan, the prevalence of GDM was reported to be $26 \% .^{12}$

Sürücü, Besen, Duman and Erbil ${ }^{13}$ state that stress can cause increased blood glucose levels and can lead to unhealthy behaviors such as binge eating or consumption of unhealthy food. The first-line management for GDM is biological and lifestyle-based, with a diet of low glycemic index and improved physical activity. ${ }^{14}$ The second and equally important dimension to managing GDM is psychological. Women with GDM suffer a high level of stress during pregnancy and it is seen that diabetes can extend even after childbirth. ${ }^{15}$ The stress of being diagnosed with gGDM while the world was facing a deadly pandemic was hypothesized to be a source of extreme trauma for expectiant mothers. Current research proposed a solution-based psycho-social dimension to intervene in the trauma. We have designed a workable theoretical model to help women suffering from GDM during the COVID-19 pandemic by connecting the family pattern theory with posttraumatic growth (PTG).

Given the linear dependency of preciseness, congruence, and consensus, the functional and psychological need for congruence contributes to a basic social truth in family relationships. ${ }^{16}$ Supportive attitudes allow a person to express their ideas, show emotional warmth, and contain verbal messages which specifically affirm feelings of distress. In such an environment, people build a positive dialogue atmosphere that is necessary for cognitive appraisal. Partner supportive communication (PSC) is a characteristic that can help a mother during pregnancy by eliciting thoughts, feelings, demonstrating good listening, displaying care, and showing empathy. ${ }^{17}$ Effective listening and elicitation of thoughts and emotions that build conversational spaces for anxious individuals can restructure their thoughts and emotions. ${ }^{18}$ According to Cordova, Cunningham, Carlson and Andrykowski, ${ }^{19}$ if trauma signs are minimal or even severe, the psychological development is potentially inhibited. Previous research observed that people experience positive growth after stressful life events. ${ }^{20}$ More clearly and broadly, PTG is often considered as a method for discovering the significance and understanding the after effects of traumatic and adverse events. Although there are several ways a person can draw significance from an event, rewriting one's life story is the mechanics from which individuals make sense of the traumatic experience and improve cognition and behavioral processing. ${ }^{21}$

In other words, these factors often intersect with each other, such that the influence of the family environment on PTG is proposed to be moderated by the strength of PSC. Therefore, it is rarely enough to examine one dimension without testing the other. ${ }^{22}$ The purpose of the current study is to enhance the awareness of mental health for women combating GDM during a pandemic. To date, the impact of family environment on PTG, along with the moderating role of PSC for the traumatized expectant mothers has never been explored. To address the possibility of an intervention, the current study aimed to explore the impact of the family environment on PTG in mothers with GDM. It $i$ also reinforces to health practitioners that obesity and the glucose rate increase in blood during pregnancy might not be the only reason for GDM.

\section{Methodology \\ Sample and Procedure}

The research included a sample of 200 women with a recent diagnosis of GDM in their first pregnancy. Data were collected from government and private hospitals of South Punjab in Pakistan during the first wave of COVID-19 (1 June 2020-30 January 2021). During this time all the registered patients for antenatal care were included in the research, however, among 1507 cases, 756 fell under the inclusion criteria and only 201 participants were systematically diagnosed to have GDM. One questionnaire was discarded due to insufficient responses. Responses were collected through paper-pencil questionnaires and the average time for answering the questionnaire was 20 minutes. Data collection was 
carried out in maternity clinics with referrals from respondents' concerned gynecologists. Patients were screened by the doctors in terms of a 75-g 2-hour oral glucose tolerance test, a criterion classified by the International Association of Diabetes and Pregnancy Study Group. Pregnant women with pre-GDM were excluded. In response to their time, respondents were provided 20 minute counseling sessions to help them cope with the stress associated with GDM. All participants provided informed consent to take part in this study. Descriptive analysis of continuous demographic variable showed $36 \%$ of participants were aged between 21 and 27 years, $34 \%$ between 28 and 34 years, $25 \%$ between 35 tand 41 years, and 5\% between 42 and 48 years. To avoid the role of confounding factors the inclusion criteria limited the intake of participants to those in their first pregnancy.

\section{Measures}

The three measures were the PSC scale, PTG inventory, and family environment scale, which were adapted from the previous researches. PSC was measured by the PSC Scale comprised of 23 items and a 5-point Likert scale. PSC was assessed in terms of four sub-levels provided by the initial factorial analysis. ${ }^{23}$ Post Traumatic Growth was assessed by Post Traumatic Growth Inventory by Tedeschi and Calhoun. ${ }^{24}$ The inventory comprised of 21 items and a 7-point Likert scale ranging from 0 (Not effect of trauma) to 6 (extreme effect). Originally the inventory had four sub-levels (relating to others, new possibilities, personal strength, spiritual change, and appreciation of life) to PTG, but this research considered only the total score. To evaluate the effect of family environment on the PTG of women recently diagnosed with GDM, this research adapted the Family satisfaction scale (FSS) by Olson and Wilson ${ }^{25}$ and Family communication scale (FCS) by Olson, Gorall and Tiesel. ${ }^{26}$ FSS intended to evaluate the degree of satisfaction that a family member has associated with her family system. It is based on 10 items and a 5-point Likert scale ranging from 1 (very dissatisfied) to 5 (extremely satisfied). FCS is also comprised of ten items and a 5-point Likert scale ranging from 1 (strongly disagree) to 5 (strongly agree).

\section{Data Analysis}

Partial Least Square Structural Equation Modeling (PLSSEM) was employed to analyze the data and perform empirical testing of the theoretical model. According to Hair Jr, Sarstedt, Hopkins and Kuppelwieser ${ }^{27}$ research must use PLS-SEM if the tested theoretical model is an extension of the current structural theory. Current research is exploratory by nature and meets the requirement. Secondly, with small sample sizes, PLS-SEM is known to display high statistical power. ${ }^{28}$ Thirdly, it is recommended for data with non-normal distribution and in our data, some values of skewness $(-2.441$ to -0.053$)$ and kurtosis $(5.835$ to 0.065$)$ exceed \pm 2 . Hence the data was violating normality. The use of PLS-SEM brings appropriate and robust results, with highly skewed data. ${ }^{27}$

Proposed hypotheses were tested using the two-step approach where the measurement model examined the reliability and validity of the measures and the structural model examined the significance and strength of the hypothesized relationships. The bootstrapping sample, 5000 re-sample was used.

\section{Results}

\section{Assessment of the Measurement Model}

Following the suggestions of Hair, Celsi, Ortinau and Bush, ${ }^{29}$ the measurement model assessed the reliability, convergent and discriminant validity. Convergent validity was assessed by the factor loadings on the measures and Average Variance Extracted (AVE). From the analysis, it was revealed that no item was required to be removed from the model because the factor loadings were all above 0.60 . The results of the model are shown in Table 1.

As shown in Table 1, all the factor loadings are above 0.60 and indicators were significant at $p<0.001$. The t-values ranged from 19.774 83.550. The scale reliability was assessed by Cronbach's $\alpha$ which was greater than

Table I Validity, Reliability and Descriptive Statistics of Latent Constructs

\begin{tabular}{|l|c|c|c|c|c|c|}
\hline Construct & Actual Range & Mean & SD & AVE & Composite Reliability & Cronbach's $\alpha$ \\
\hline Post Traumatic Growth & $1.14-5.46$ & 4.387 & 1.297 & 0.698 & 0.920 & 0.937 \\
Partner Supportive Communication & $2.20-4.55$ & 4.07 & 0.915 & 0.697 & 0.901 & 0.783 \\
Family Environment & $1.87-4.67$ & 4.97 & 0.957 & 0.716 & 0.859 & 0.759 \\
\hline
\end{tabular}


recommended 0.70 thresholds ${ }^{29}$ suggesting that the measures were all robust. The CR ranged from 0.826 to 0.912 which also exceeds the required threshold. Convergent validity was tested using AVE. The AVE for PSC scale, PTG inventory, and family environment scale was above the 0.5 threshold. ${ }^{27}$ The guidelines by ${ }^{30}$ were followed to analyze the discriminant validity of the proposed model. As explained in Table 2, the square root of the AVE for all constructs within the matrix diagonal is higher than the related correlation value in the corresponding rows and columns. Therefore, the quality of the reflective model is acceptable.

Furthermore, cross-loadings of reflective construct indicators were examined in order to test the discriminant validity of the model. According to, ${ }^{28}$ indicators of the reflective measurement model must have the highest loadings on their underlying latent constructs compared to other constructs of the structural model. Results showed that the measurement scale items have a higher loading on their corresponding underlying construct. Therefore, the cross-loading criteria are met and suggest satisfactory discriminant validity for the measurement model.

\section{Assessment of the Structural Model}

Structural model intended to evaluate the relationships among constructs. Standardized root means square residual (SRMR) was used to assess the overall model fit. ${ }^{31}$ The research model for this research indicated a value of 0.071 which is less than the suggested threshold of 0.08 and indicates a good model fit. $^{32}$ The structural model was assessed using determination coefficients of endogenous variables $\left(\mathrm{R}^{2}\right)$ and the path coefficients of all latent variables. ${ }^{33,34}$ The predictive power of the structural model was assessed by $\mathrm{R}^{2}$ criterion. ${ }^{35} \mathrm{R}^{2}$ values were above the required 0.10 level $^{36}(\mathrm{PTG}=0.689)$. Moreover, the effect size was examined by $\mathrm{f}^{2}(\mathrm{PTG}=0.961)$ which suggests the change in $R^{2}$ if any specific exogenous construct was omitted. ${ }^{37}$

To examine the moderating effect of PSC, this study has multiplied sub-levels of PSC with a family environment to individually analyze the impact of different styles of communication on PTG (Figure 1). As a result of 200

Table 2 Fornell-Larcker Criterion for Discriminant Validity

\begin{tabular}{|l|l|l|l|}
\hline Construct & PTG & PSC & FE \\
\hline Post Traumatic Growth (PTG) & 0.857 & & \\
Partner Supportive Communication (PSC) & 0.567 & 0.740 & \\
Family Environment (FE) & 0.556 & 0.643 & 0.763 \\
\hline
\end{tabular}

iterations (Table 3), we found a direct significant relationship between family environment and PTG $(\beta=0.507$, $t$-value $=7.582, p=0.000)$. Moreover, elicitation of thoughts and feelings $(\beta=0.109, t$-value $=3.501, p=$ 0.001 ), effective listening $(\beta=-0.144, t$-value $=1.928$, $p=0.054)$, and communication that displayed care towards the partner $(\beta=-0.209, t$-value $=4.850, p=$ $0.005)$ significantly moderated the relationship between family environment and PTG.

According to Table 3, displaying care for PSC significantly moderated the relationship between family environment and PTG. Elicitation of thoughts for PSC significantly moderated the relationship between family environment and PTG.

\section{Discussion}

The results of our research significantly suggest a strong relationship between PTG and dimensions of PSC, such as displaying care towards a partner in distress, effectively listening to her feelings and validating them, elicitation of thoughts and feelings of a partner by providing a safe space to express every negative thought that might cause long-term emotional distress and showing empathy to the partner by sharing her feelings and understanding them. Furthermore, the family environment showed significant interaction with dimensions of PSC and played a strong role in determining the PTG of patients with a recent diagnosis of GDM.

GDM is a major health concern with a complex treatment plan that requires a multidisciplinary approach. In addition to the biological management through diet, medication, and physical activity, a mandatory management plan should be designed to deal with psychological aspects. A recent systematic review of psychological challenges associated with GDM suggested significant challenges of socio-cultural issues, information communication, lifestyle change, and change in health care routine. ${ }^{38}$ Current research intended to propose a potentially strengthening management dimension against GDM because a support package tailored to psychological needs might assist the health care system in improving the management and prognosis of individuals. GDM at a higher rate worldwide is alarming, especially among Asian women. ${ }^{39}$ A woman's psychological well-being is overall affected by the family environment and it was purported that PTG can be mitigated by the influence of family environment and PSC..$^{40}$ Data was collected during the initial phase of the COVID-19 pandemic, making this 


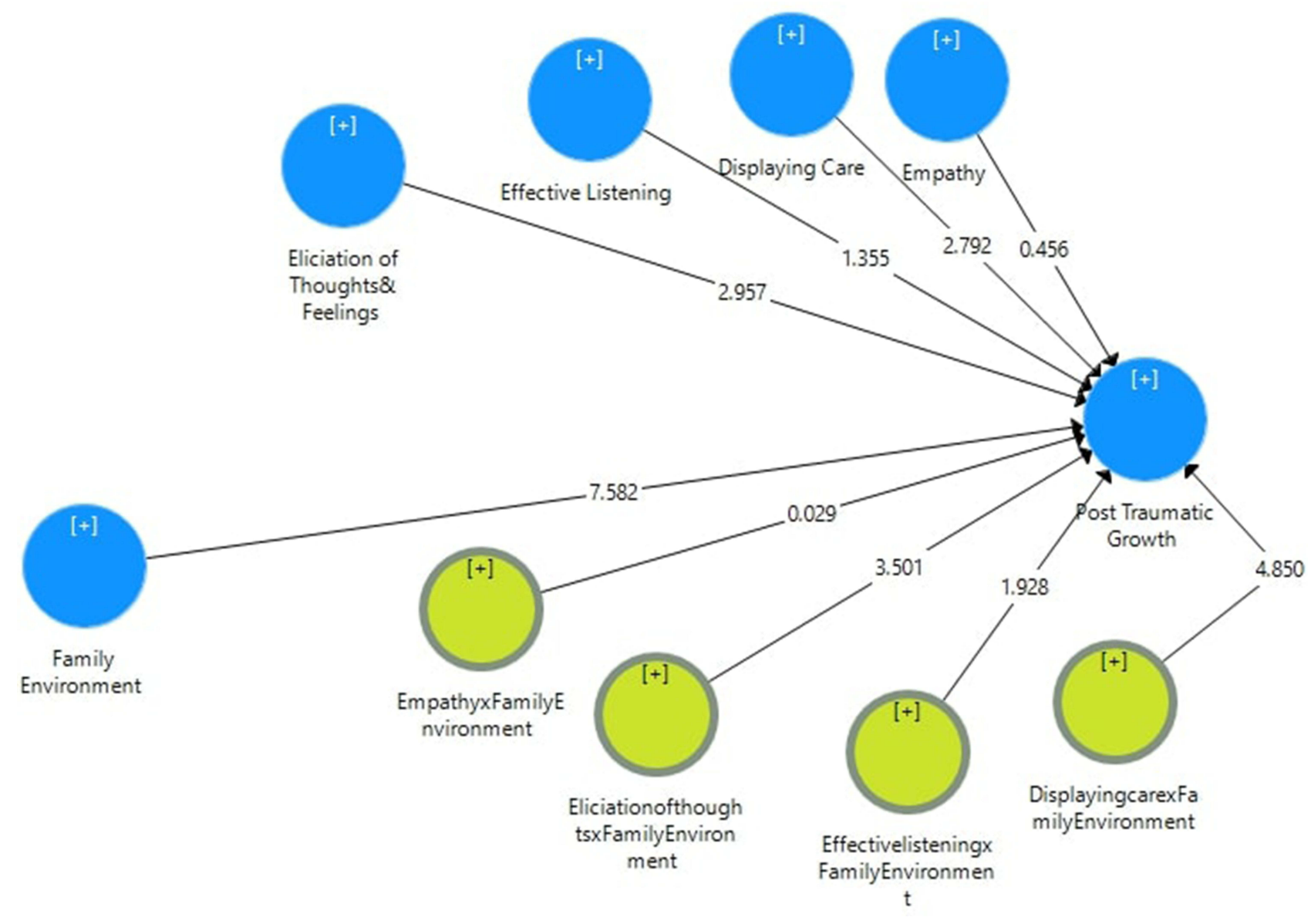

Figure I The Structural Model with Estimates

research work a unique study concerning the variable set and time frame.

According to Tian and Solomon, ${ }^{23}$ supportive conversation aids the cognitive processing of a stressful situation by providing a space for distressed individuals to articulate, elaborate, and clarify relevant thoughts and feelings. The results of the present study affirmed it and accepted the hypothesis revealing that PSC fosters the association between family environment and PTG among women, thus strengthening the relationship between family environment and PTG. It adds to the previous literature in this regard. ${ }^{41,42}$ The findings of the study may help GDM patients, their family members, and professionals to mitigate the psychological effects of being diagnosed with a challenging disease during the pandemic and then finding an appropriate recovery process. The results of this

Table 3 The Structural Model and Path Estimates

\begin{tabular}{|c|c|c|c|c|c|}
\hline Construct and Measurement Items & $\boldsymbol{\beta}$ & M(ST-D) & $\mathbf{t}$ & $\mathbf{p}$ & $95 \% \mathrm{Cl}$ \\
\hline Displaying care $\rightarrow$ post traumatic growth & 0.159 & $0.1601(0.057)$ & 2.792 & 0.005 & {$[0.045,0.261]$} \\
\hline Displaying care $\times$ family environment $\rightarrow$ post traumatic growth & -0.209 & $-0.209(0.043)$ & 4.850 & 0.000 & {$[-0.298,-0.134]$} \\
\hline Effective listening $\rightarrow$ post traumatic growth & 0.097 & $0.109(0.072)$ & 1.355 & 0.176 & {$[-0.023,-0.266]$} \\
\hline Effective listening $\times$ family environment $\rightarrow$ post traumatic growth & -0.144 & $-0.14 \mid(0.075)$ & 1.928 & 0.054 & {$[-0.282,0.009]$} \\
\hline Elicitation of thoughts and feelings $\rightarrow$ post traumatic growth & 0.234 & $0.239(0.079)$ & 2.957 & 0.003 & {$[0.090,0.412]$} \\
\hline Elicitation of thoughts and feelings $\times$ family environment $\rightarrow$ post traumatic growth & 0.179 & $0.172(0.05 I)$ & 3.501 & 0.001 & {$[0.060,0.27 I]$} \\
\hline Empathy $\rightarrow$ post traumatic growth & -0.018 & $-0.016(0.039)$ & 0.456 & 0.648 & {$[-0.091,0.065]$} \\
\hline Empathy $\times$ family environment $\rightarrow$ post traumatic growth & 0.002 & $0.005(0.057)$ & 0.029 & 0.977 & {$[-0.106,0.119]$} \\
\hline Family environment $\rightarrow$ post traumatic growth & 0.507 & $0.488(0.067)$ & 7.582 & 0.000 & {$[0.346,0.606]$} \\
\hline
\end{tabular}


research are encouraging for both patients and their family members, especially the support from a partner through effective communication and is congruent with the findings of previous studies. ${ }^{43}$

This research implies that family members or significant others have broader effects in terms of well-being, and PTG of a person with GDM. It provides a better understanding of the determinants of PTG among GDM patients. Previous researche has studied family relationships and PTG and found that family factors such as communication predicted PTG, in addition to coping strategies ${ }^{44}$ Communication seemed to be a potent predictor of PTG as suggested by Ledbetter, ${ }^{45}$ supportive communication with a partner has a moderating role between interpersonal relationships and psychological growth. The findings of our study are congruent with previous literature, suggesting a boosting role of family environment and partner communication in determining PTG. For instance, Tian and Solomon, ${ }^{23}$ PSC and its factors significantly helped in positive psychological growth. Moreover, Chipuer and Villegas ${ }^{46}$ stated that the family environment had a positive correlation between its factors and partner communication.

\section{Limitations}

A few limitations should be considered when interpreting the findings of this work. First, the outcomes of this study are only applicable to women who have had high-risk pregnancies. Future studies should examine whether the findings of the current study can be extend to the low-risk women. Secondly, the current sample was collected during a pandemic, limiting the generalizability of our findings.

\section{Conclusion}

The ultimate goal of this study was to find out how PSC affects the association between family environment and PTG for mothers with GDM. This correlational study on the sample from different medical hospitals and maternity centers of South Punjab of Pakistan concluded that PSC has a strengthening influence on the relationship between family environment and PTG of women diagnosed with GDM during a pandemic. Given the significant findings and implications, further studies are suggested to focus on cross-cultural research designs.

\section{Ethical Considerations}

The approval for research was sorted from Ethics Review Board of Department of Psychology, Institute of Southern
Punjab, Multan. Current research was conducted and written in accordance with the declaration of Helsinki.

\section{Acknowledgment}

This study was funded by the National Social Science Foundation of China (Grant Number 20BSH096) to Zhidan Wang.

\section{Disclosure}

The authors report no conflicts of interest in this work.

\section{References}

1. Justman N, Shahak G, Gutzeit O, et al. Lockdown with a price: the impact of the COVID-19 pandemic on prenatal care and perinatal outcomes in a tertiary care center. Israel Med Assoc J. 2020;22 (9):533-537.

2. Rasmussen SA, Smulian JC, Lednicky JA, Wen TS, Jamieson DJ. Coronavirus disease 2019 (COVID-19) and pregnancy: what obstetricians need to know. Am J Obstet Gynecol. 2020;222(5):415-426. doi:10.1016/j.ajog.2020.02.017

3. Katz DL. Leveraging the Exit of Diabesity: we suffer from obesity and diabetes because we eat too much and exercise too little. Solving the problem is hard but not complicated. IEEE Pulse. 2014;5 (3):18-21. doi:10.1109/MPUL.2014.2309574

4. Cecchetto C, Aiello M, Gentili C, Ionta S, Osimo SA. Increased emotional eating during COVID-19 associated with lockdown, psychological and social distress. Appetite. 2021;160:105122. doi:10.1016/j.appet.2021.105122

5. Serván PR. Obesity and diabetes. Nutr Hosp. 2013;28(5):138-143.

6. Zhang J, Zhang Y, Huo S, et al. Emotional eating in pregnant women during the COVID-19 pandemic and its association with dietary intake and gestational weight gain. Nutrients. 2020;12(8):2250. doi: $10.3390 /$ nu 12082250

7. Kalra S. Diabesity. J Pak Med Assoc. 2013;63(4):532-534.

8. Fedullo AL, Schiattarella A, Morlando M, et al. Mediterranean diet for the prevention of gestational diabetes in the Covid-19 era: implications of Il-6 in diabesity. Int J Mol Sci. 2021;22(3):1213. doi:10.3390/ijms22031213

9. Di Mascio D. Maternal and Perinatal Outcomes of Pregnant Women with SARS-COV-2 infection. Ultrasound Obstet Gynecol. 2020;57:232.

10. Elkafrawi D, Joseph J, Schiattarella A, Rodriguez B, Sisti G. Intrauterine transmission of COVID-19 in Pregnancy: case report and review of literature. Acta Bio Med. 2020;91(3):e2020041.

11. Lee KW, Ching SM, Ramachandran V, et al. Prevalence and risk factors of gestational diabetes mellitus in Asia: a systematic review and meta-analysis. BMC Pregnancy Childbirth. 2018;18(1):1-20. doi:10.1186/s12884-018-2131-4

12. Riaz M, Nawaz A, Masood SN, Fawwad A, Basit A, Shera A. Frequency of gestational diabetes mellitus using DIPSI criteria, a study from Pakistan. Clin Epidemiol Glob Health. 2019;7 (2):218-221. doi:10.1016/j.cegh.2018.06.003

13. Sürücü HA, Besen DB, Duman M, Erbil EY. Coping with stress among pregnant women with gestational diabetes mellitus. J Caring Sci. 2018;7(1):9. doi:10.15171/jcs.2018.002

14. Schiattarella A, Lombardo M, Morlando M, Rizzo G. The impact of a plant-based diet on gestational diabetes: a review. Antioxidants. 2021;10(4):557. doi:10.3390/antiox10040557

15. Buchanan TA, Xiang AH, Page KA. Gestational diabetes mellitus: risks and management during and after pregnancy. Nat Rev Endocrinol. 2012;8(11):639-649. doi:10.1038/nrendo.2012.96 
16. Koerner AF, Schrodt P. An introduction to the special issue on family communication patterns theory. J Fam Commun. 2014;14(1):1-15. doi:10.1080/15267431.2013.857328

17. Priem JS, Solomon DH. Emotional support and physiological stress recovery: the role of support matching, adequacy, and invisibility. Commun Monogr. 2015;82(1):88-112. doi:10.1080 03637751.2014 .971416

18. Jones SM, Wirtz JG. How does the comforting process work? An empirical test of an appraisal-based model of comforting. Hum Commun Res. 2006;32(3):217-243. doi:10.1111/j.14682958.2006.00274.x

19. Cordova MJ, Cunningham LL, Carlson CR, Andrykowski MA. Posttraumatic growth following breast cancer: a controlled comparison study. Health Psychol. 2001;20(3):176. doi:10.1037/02786133.20.3.176

20. Jayawickreme E, Blackie LE. Post-traumatic growth as positive personality change: evidence, controversies and future directions. Eur J Pers. 2014;28(4):312-331. doi:10.1002/per.1963

21. Park CL. Making sense of the meaning literature: an integrative review of meaning making and its effects on adjustment to stressful life events. Psychol Bull. 2010;136(2):257. doi:10.1037/a0018301

22. Fitzpatrick MA, Koerner AF. Family communication schemata: effects on children's resiliency. In: The Evolution of Key Mass Communication Concepts: Honoring Jack M McLeod. 2005:115-139.

23. Tian X, Solomon DH. Grief and post-traumatic growth following miscarriage: the role of meaning reconstruction and partner supportive communication. Death Stud. 2020;44(4):237-247. doi:10.1080/ 07481187.2018.1539051

24. Tedeschi RG, Calhoun LG. The posttraumatic growth inventory: measuring the positive legacy of trauma. J Trauma Stress. 1996;9 (3):455-471. doi:10.1002/jts.2490090305

25. Olson DH, Wilson M. Family Satisfaction Scale. Minneapolis, MN: Life Innovations; 1995.

26. Olson DH, Gorall DM, Tiesel JW. Faces IV package. Minneapolis, $\mathrm{MN}$ : Life Innovations. 39; 2004;12-13.

27. Hair JF Jr, Sarstedt M, Hopkins L, Kuppelwieser VG. Partial least squares structural equation modeling (PLS-SEM): an emerging tool in business research. Eur Busi Rev. 2014;26:106-121.

28. Hair JF Jr, Sarstedt M, Ringle CM, Gudergan SP. Advanced Issues in Partial Least Squares Structural Equation Modeling. saGe publications; 2017.

29. Hair JF, Celsi M, Ortinau DJ, Bush RP. Essentials of Marketing Research. Vol. 2. New York, NY: McGraw-Hill/Irwin; 2010.

30. Fornell C, Larcker DF. Evaluating structural equation models with unobservable variables and measurement error. $J$ Marketing Res. 1981;18(1):39-50. doi:10.1177/002224378101800104

31. Henseler J, Hubona G, Ray PA. Using PLS path modeling in new technology research: updated guidelines. Ind Manag Data Syst. 2016;116(1):2-20. doi:10.1108/IMDS-09-2015-0382

32. Hu L, Bentler PM. Cutoff criteria for fit indexes in covariance structure analysis: conventional criteria versus new alternatives. Struct Equ Modeling. 1999;6(1):1-55. doi:10.1080/10705519909540118
33. Sarstedt M, Ringle CM, Smith D, Reams R, Hair JF Jr. Partial least squares structural equation modeling (PLS-SEM): a useful tool for family business researchers. J Fam Bus Strategy. 2014;5(1):105-115. doi:10.1016/j.jfbs.2014.01.002

34. Memon AH, Rahman IA. SEM-PLS analysis of inhibiting factors of cost performance for large construction projects in Malaysia: perspective of clients and consultants. Sci World J. 2014;2014:1-9. doi:10.1155/2014/165158

35. Chin WW. Commentary: issues and opinion on structural equation modeling. JSTOR. 1998;22:vii-xvi.

36. Kalman ME, Monge P, Fulk J, Heino R. Motivations to resolve communication dilemmas in database-mediated collaboration. Communic Res. 2002;29(2):125-154. doi:10.1177/ 0093650202029002002

37. Cohen J. Set correlation and contingency tables. Appl Psychol Meas. 1988;12(4):425-434. doi:10.1177/014662168801200410

38. Siahkal SF, Javadifar N, Najafian M, Iravani M, Zakerkish M, Heshmati R. The psychosocial challenges associated with gestational diabetes mellitus: a systematic review of qualitative studies. Prim Care Diabetes. 2021. doi:10.1016/j.pcd.2021.09.003

39. Fatima SS, Rehman R, Alam F, Madhani S, Chaudhry B, Khan TA. Gestational diabetes mellitus and the predisposing factors. J Pak Med Assoc. 2017;67(2):261.

40. DiPietro JA. Maternal stress in pregnancy: considerations for fetal development. J Adolesc Health. 2012;51(2):S3-S8. doi:10.1016/j. jadohealth.2012.04.008

41. Kaptein S, Evans M, McTavish S, et al. The subjective impact of a diagnosis of gestational diabetes among ethnically diverse pregnant women: a qualitative study. Can J Diabetes. 2015;39(2):117-122. doi:10.1016/j.jcjd.2014.09.005

42. Nielsen KK, Dahl-Petersen IK, Jensen DM, et al. Protocol for a randomised controlled trial of a co-produced, complex, health promotion intervention for women with prior gestational diabetes and their families: the Face-it study. Trials. 2020;21(1):1-12. doi:10.1186/s13063-020-4062-4

43. Barskova T, Oesterreich R. Post-traumatic growth in people living with a serious medical condition and its relations to physical and mental health: a systematic review. Disabil Rehabil. 2009;31 (21):1709-1733. doi:10.1080/09638280902738441

44. Svetina M, Nastran K. Family relationships and post-traumatic growth in breast cancer patients. Psychiatr Danub. 2012;24 (3):298-306.

45. Ledbetter AM. Family communication patterns and communication competence as predictors of online communication attitude: evaluating a dual pathway model. J Fam Commun. 2010;10(2):99-115. doi:10.1080/15267431003595462

46. Chipuer HM, Villegas T. Comparing the second-order factor structure of the Family Environment Scale across husbands' and wives' perceptions of their family environment. Fam Process. 2001;40 (2):187-198. doi:10.1111/j.1545-5300.2001.4020100187.x
International Journal of Women's Health

\section{Publish your work in this journal}

The International Journal of Women's Health is an international, peerreviewed open-access journal publishing original research, reports, editorials, reviews and commentaries on all aspects of women's healthcare including gynecology, obstetrics, and breast cancer. The manuscript management system is completely online and includes a very quick and fair peer-review system, which is all easy to use Visit http://www.dovepress.com/testimonials.php to read real quotes from published authors. 